\title{
Feeding Tube Dependency
}

National Cancer Institute

\section{Source}

National Cancer Institute. Feeding Tube Dependency. NCI Thesaurus. Code C156238.

The inability of a patient to received their nutrition other than through a feeding tube. 